\title{
Sertoli-Leydig cell tumor (arrhenoblastoma) in adolescent age group
}

\author{
Swarnalata Samal, Amogh Chimote*, Rohit Juneja, Madhuprita Agrawal
}

Department of Obstetrics and Gynaecology, Faculty of Medicine, J.N.M.C., Sawangi (Meghe), Wardha, Maharashtra, India

Received: 11 October 2013

Accepted: 27 October 2013

*Correspondence:

Dr. Amogh Chimote,

E-mail: amoghdr@yahoo.co.in

(C) 2013 Samal S et al. This is an open-access article distributed under the terms of the Creative Commons Attribution Non-Commercial License, which permits unrestricted non-commercial use, distribution, and reproduction in any medium, provided the original work is properly cited.

\begin{abstract}
Arrhenoblastoma, also known as Sertoli-Leydig cell tumors or androblastomas, are very rare neoplasm of the ovaries, resulting in the overproduction of the male hormone testosterone. This is a rare tumour which accounts for less than $0.5 \%$ of all ovarian tumours. These tumours are found in women of all age groups, but are most common in young women. Presence of an ovarian tumour plus hormonal disturbances suggests a Sertoli-Leydig cell tumour. Patients present with a recent history of progressive masculinisation. Masculinisation is preceded by anovulation, oligomenorrhoea, amenorrhoea and defeminisation. Arrhenoblastomas are generally unilateral benign tumour; do not normally spread beyond the ovary, occurring in reproductive age. This work summarizes the morphological and immunohistochemical characteristics of this tumour in a 15 -year old girl with clinical signs of virilisation. A 14 year old female admitted with abdominal distension, change in voice, male pattern balding and clitoromegaly in the dept. of Ob/Gy A.V.B.R.H. (Acharya Vinoba Bhave Rural Hospital) Sawangi, Wardha. Investigations included Sonography C.T scan, ascetic tap, Serum testosterone was done. She was managed by exploratory Laparotomy and follow up was advised. On follow up her serum testosterone levels and sonography was done. Here we are representing the case.
\end{abstract}

Keywords: Sertoli-Leydig cell tumor, Ferriman-Galleway scoring, Hirsutism, Virilisation

\section{INTRODUCTION}

Arrhenoblastomas, also known as Sertoli-Leydig cell tumors or androblastomas, are very rare neoplasm of the ovaries, resulting in the overproduction of the male hormone testosterone. This is a rare tumour which accounts for less than $0.5 \%$ of all ovarian tumors. ${ }^{1}$ These tumours are found in women of all age groups, but are most common in young women. Presence of an ovarian tumour plus hormonal disturbances suggests a SertoliLeydig cell tumour. Patients present with a recent history of progressive masculinisation. Masculinisation is preceded by anovulation, oligomenorrhoea, amenorrhoea and defeminisation. Arrhenoblastomas are generally unilateral benign tumour; do not normally spread beyond the ovary, occurring in reproductive age.
The percentage of Sertoli-Leydig cell tumours, manifesting endocrine activity has not been established, but it most probably amounts to about 50\%, while virilisation develops in about $1 / 3$ of patients. In tumours showing hormonal activity the testosterone level is elevated, while the DHEAS level is within the normal range. ${ }^{7}$ Asymmetrical ovarian volume, especially if accompanied by unusually high testosterone concentrations, very probably points to an ovarian tumour, and when dealing with a patient with progressive hirsutism and/or virilisation, even with a negative ultrasound finding, the clinician should remain suspicious and careful and request control examinations. ${ }^{7}$ 


\section{CASE REPORT}

A 14 year old female came to the OB/GY O.P.D. A.V.B.R.H, Sawangi, Wardha with complaints of abdominal distension, hoarseness in voice, thinning of hair and oligomenorrhoea (60-90 days very scanty periods ) with no dysmenorrhoea or passage of clots. LMP being 17/4/12 her menarche was 13 yrs and she had normal menses to begin with. The menses were regular lasted for 3-4 days and had a regular interval between 2 cycles. 3 months ago she complained of irregular and scanty menses with no medical intervention. The patient and the relatives also noticed a change in voice along with thinning and loss of scalp hair and increase in the amount of body hair. 1 month ago the patient noticed abdominal distension which was minimal but was causing discomfort.

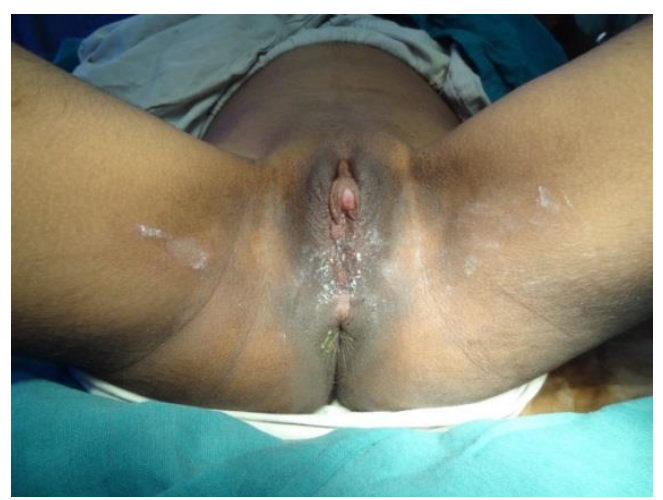

Figure 1: Clitoromegaly.

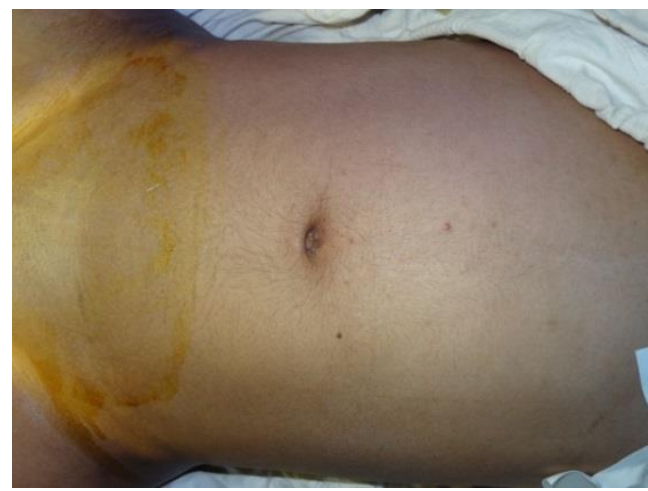

Figure 2: Abdominal distention and male pattern hair distribution.

On examination virilising characters such as bushy eyebrows, moustache and beard were present. The patient had masculine built and broad shoulders. Change in voice was present and was hoarse. The modified FerrimanGalleway scoring method was used for evaluation and quantifying hirsutism in this case. Within this system, abnormal hair distribution is assessed in nine body areas and scored from 0 to. Increasing numeric scores correspond to greater hair density within a given area. Many investigators define hirsutism as a score of 8 or greater using the modified version. 4 (The score was calculated to 18 which indicated virilisation) per abdomen examination revealed distended abdomen measuring $68 \mathrm{~cm}$ with guarding and tenderness. Since the patient was unmarried no $\mathrm{p} / \mathrm{s}$ or $\mathrm{p} / \mathrm{v}$ examination was done but local examination of the genitalia showed clitoromegaly and male pattern distribution of pubic hair. Breast development and breast buds were present but under developed.

Investigations revealed normal haemoglobin and counts. Hormone analysis in the form of serum Testosterone of $584 \mathrm{ng} / \mathrm{dL}$ was reported. Imaging studies such as USG and CT scan were done. USG revealed a heterogeneous mass in pelvic region near the right ovary which could not be differentiated from the right ovary. The uterus was found to have normal size, shape and echo texture. The left ovary was of normal size and shape with no abnormal mass or cysts.

CT scan showed a heterogeneous pelvic mass extending to supra umbilical region with eccentric cystic necrotic area displacing adjacent bowel loops. Right ovary could not be differentiated from the mass. These features were evident of a malignant lesion in right adnexa with moderate ascites. To confirm the diagnosis ascetic fluid tapping was done under the guidance of USG and sent for cytology. Ascetic fluid cytology revealed a transudative picture with no malignant cells.

Decision was taken to operate the patient and explore the mass. Exploratory Laparotomy was done for this patient and a large Tubo-Ovarian mass of $10 \times 8 \mathrm{~cm}$ was found and right salpingo-oophorectomy was done and the specimen sent for histopathology examination. Left ovarian biopsy was taken to rule out the spread from the mass and sent for histopathology examination.

Histopathological examination showed features suggestive of a sex cord stromal tumour (Sertoli-Leydig sell tumours) of intermediate differentiation. Right fallopian tube and Left ovarian biopsies were Unremarkable. No Omental involvement was found.

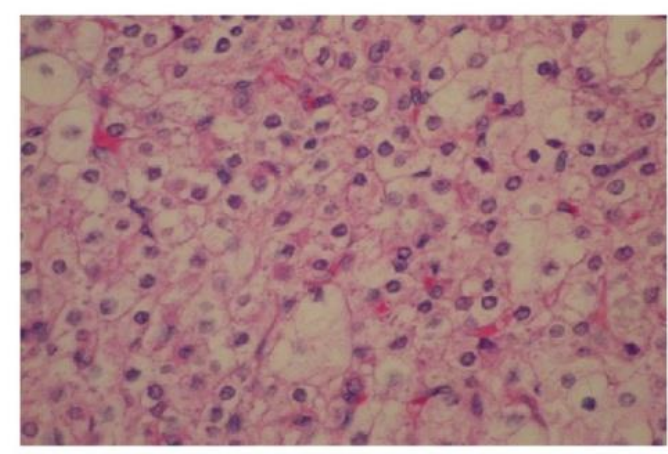

Figure 3: Histologic section obtained from the gross tumor. Note the eosinophilic and vacuolated appearance of the cellular structure characteristic of steroid cell, not otherwise specified. 
The patient came for follow up after 4 months and here USG and testosterone levels were repeated which showed serum testosterone levels: $53 \mathrm{ng} / \mathrm{dL}$ (after 4 months) as compared serum testosterone of $584 \mathrm{ng} / \mathrm{dL}$ at the time of admission. Reduction in hirsutism determined by decrease in the Ferriman Galleway scoring (score 8) Regular menstrual periods with normal flow pattern and duration of bleeding.

Sonography showed normal sized uterus, Endometrium of $9 \mathrm{~mm}$ in thickness no involvement of the left side adnexa and left ovary with normal size, shape and echo texture. No focal mass or lesion seen.

\section{DISSCUSSION}

The Sertoli-Leydig cell (S-L) tumour (androblastoma) is a gonadal tumour of sex-cord- stromal tumour. This type in which the components to a greater or lesser extent recapitulate the cells of the testis at various stages of development. ${ }^{2}$ The term "androblastoma" is preferred by other investigators because it reflects the wide range of differentiation of these tumors. ${ }^{1}$ Both designations have received wide acceptance and are listed as alternatives in the International Histological Classification of Tumours. The older term "arrhenoblastoma," introduced by Robert Meyer, although widely used for the tumours of this group that contain both Sertoli and Leydig cell elements, is not considered appropriate because it carries the connotation of masculinisation. The tumour is said to be approximately one-fifth as common as the corresponding sex-cord-stromal tumour recapitulating the cells of the ovary, the granulose theca cell tumour, and accounts for less than $0.5 \%$ of all ovarian tumors.' ${ }^{1}$

The rationale for removal of the neoplasia was determined by normalization of Testosterone levels and increase of serum gonadotrophins with subsequent restoration of a normal responsiveness to LHRH and resumption of an ovulatory menstrual cycle. This observation suggests that the high $\mathrm{T}$ levels played a primary role in the pathogenesis of the gonadotrophins suppression and anovulation. Recovery of acne was complete whereas hirsutism score was reduced but still elevated after one year. This may be due to postoperative DHEAs levels slightly above the normal range, indicating the presence of adrenal hyperandrogenism. ${ }^{4}$

The most important prognostic factors in these tumours are their stage and degree of differentiation. In a review of 207 cases by Young and Scully in $1985^{5}$, all welldifferentiated tumours were benign, whereas $11 \%$ of tumours with intermediate differentiation, $59 \%$ of tumours with poor differentiation, and $19 \%$ of those with heterologous elements were malignant. In another study of 64 patients who had intermediate or poorly differentiated SLCT, a survival rate of $92 \%$ was noted at both 5 and 10 years. $^{6}$ the heterologous component comprising of smooth muscle, an uncommon element and the epithelial element of the tumour consisting of solid, tubular and foci of retiform pattern imply a poor prognosis. $^{9}$

The majority of these tumours are unilaterally localized, and conservative surgery is sufficient. However, these tumours exhibit a variety of histological patterns, which are significant prognostic factors. To date, no standard therapy exists. In a study by Chen et al, one patient whose tumour was a poorly differentiated Sertoli-Leydig cell tumour with mesenchymal heterologous elements received adjuvant chemotherapy postoperatively but died of disease 2.5 years after surgery. The other 3 patients remained free of disease during follow-up. Conservative surgery is an appropriate treatment for young patients with Sertoli-Leydig cell tumours. Those who have poor prognostic factors may need adjuvant chemotherapy with a combination of bleomycin, etoposide and cisplatin. ${ }^{8}$

\section{CONCLUSION}

In this case study a unilateral ovarian mass was diagnosed with the help of imaging and histopathological modalities guided by hormonal marker in the form of serum testosterone. As seen by few studies mentioned above surgical approach can be considered for the treatment and for a better prognosis for patients with Sertoli-Leydig cell tumour. Although one needs to keep an open eye for the diagnosis of this tumour as $50 \%$ cases will not present with virilising changes. A thorough examination and targeted investigations can help in proper diagnosis and management of this tumour.

\section{REFERENCES}

1. Scully RE. Sex cord-stromal tumours. In: Bluestein A, Ed .Pathology of the female genital tract. New York: Springer-Verlag.

2. Roth LM, Anderson MC, Govan AD, Langley FA, Gowing NF, Woodcock AS. Sertoli- Leydig Cell Tumors:A Clinicopathologic Study of 34 Cases. Cancer. 1981 Jul 1;48(1):187-97.

3. Teilum G. Classification of testicular and ovarian androblastoma and Sertoli cell tumors. A survey of comparative studies with consideration of histogenesis, endocrinology and embryological theories. Cancer 1958; 11:769-782.

4. Tita P, Spina A, Briguglia G, Magro A, Gallo D, Finocchiaro C, Padova G, Pezzino V. Clinical features and hormonal characteristics in a case of ovarian Arrhenoblastoma. J Endocrinol Invest. 1996 Jul-Aug;19(7):484-7.

5. Young RH, Scully RE. Ovarian Sertoli-Leydig cell tumours. A clinicopathological analysis of 207 cases. Am J Surg Pathol. 1985;9:543-569.

6. Zaloudek C, Norris H. Sertoli-Leydig cell tumors of the ovary. A clinicopathological study of 64 intermediate and poorly differentiated neoplasms. Am J Surg Pathol. 1984;8:405-418.

7. Puzigaća S, Prelević G, Svetenović Z, Djuricić S, Kokan Dj, Radivojević U. Sertoli-Leydig cell 
tumour (arrhenoblastoma) in a patient with polycystic ovary syndrome: clinical, ultrasonographic, hormonal and histopathological evaluation. Srp Arh Celok Lek. 2001 May-Jun;129 Suppl 1:51-5.

8. Chen FY, Sheu BC, Lin MC, Chow SN, Lin HH. Sertoli-Leydig cell tumor of the ovary. J Formos Med Assoc. 2004 May;103(5):388-91.
9. Kataria SP, Mishra K, Dev G, Tandon R. SertoliLeydig cell tumor of ovary with heterologous element: a case report. Indian J Pathol Microbiol. 2005 Oct;48(4):493-5.

DOI: $10.5455 / 2320-1770 . i j r \operatorname{cog} 20131252$

Cite this article as: Samal S, Chimote A, Juneja R, Agrawal M. Sertoli-Leydig cell tumor (arrhenoblastoma) in adolescent age group. Int $\mathrm{J}$ Reprod Contracept Obstet Gynecol 2013;2:722-5. 